\title{
Planning a Course of a Computer Engineering Program by Bloom's Taxonomy
}

\author{
Valfredo Pilla $\mathrm{Jr}^{1}$ and Giancarlo F. Aguiar ${ }^{2,3}$ \\ 1. Department of Electronics, Federal University for Technology of Paraná, Curitiba-PR 80230-901, Brazil \\ 2. Department of Mathematics, Federal Institute of Paraná, Curitiba-PR 82530-230, Brazil \\ 3. Department of Computer Engineering, Positivo University, Curitiba-PR 81280-330, Brazil
}

Received: April 1, 2015 / Accepted: April 17, 2015 / Published: April 25, 2015.

\begin{abstract}
The planning of teaching for a course that belongs to an undergraduate program usually begins with the definition of its contents, which are derived from syllabus of a political-pedagogical project. The contents listed are organized in a sequence considered logical. A set of actions is planned, such as lectures, laboratories, among others, through which content will be developed. The previous training of the student is considered, the concurrent and subsequent courses, the context of the course inside the program, the specific and general objectives of the program. A set of assessments is also defined as part of this planning, the associated methodologies, techniques and teaching objectives. In this context, this paper focuses on the aspect of the sequencing of content, methodologies and teaching techniques in a course. For this purpose, the Bloom's Taxonomy of Educational Objectives is applied, which provides a hierarchical structure for the cognitive process. The importance of this hierarchy of knowledge is greater awareness of the teacher about the ways to be adopted in the teaching process.
\end{abstract}

Key words: Teaching organization, Bloom’s Taxonomy of Educational Objectives.

\section{Introduction}

The increased demand for bachelor programs in engineering [13] by high school graduates has been a motivator for expanding the supply of these programs in Brazil, in addition to the recognized need for professionals of this area in this country. The increased supply of places has occurred both in public institutions (Federal or State, which are free) and in private institutions (usually with cost to the student). The federal government, which holds the majority of public institutions in Brazil, provides direct support programs to students. The Federal Program "Science without Borders" award scholarships to students to perform at least part of their studies in foreign institutions. The Ministry of Education also offers other incentives, such as PBP (Schollarship for

Corresponding author: Valfredo Pilla Jr, M.Sc., research fields: education in engineering, pattern recognition and reconfigurable computing. E-mail: valfredo@utfpr.edu.br.
Permanence Program, http://permanencia.mec.gov.br/) to support needy students in federal institutions of higher education, PROUNI (University for All Program, http://siteprouni.mec.gov.br/) that offers full or partial scholarships for students of private institutions, and the FIES (Student Financing Program, http://sisfiesportal.mec.gov.br/) which provides funding to paying students from private institutions.

Associated with the expansion of demand and supply there is always the concern with the maintenance and improvement of the learning process in engineering courses in the country. In particular, Brazil has difficulties in properly train students in high school [7, 12], which makes the route of students over the engineering programs be more sinuous, sometimes even no way out [3].

According to Ref. [5], a major cause of academic evasion in engineering programs may be the lack of fit between the methods usually adopted by teachers in 
the classroom and their lack of relationship with the individual characteristics of students who evade the program.

In Ref. [11], the acquisition of knowledge and investigative attitude does not spontaneously occur by osmosis, requiring the teacher to intervene with mediation, with theoretical configuration and practical development that support the student in the process.

"With the demands of the contemporary world we live in a world where the difference is vital and apparent, the teacher, even before knowing how your students learn, the teacher should to become aware of and control the strategies that the student use to learn [9].”

In this context, teachers of these programs are subject to the challenge of finding ways to produce a teaching process that is viable, attractive, while the teaching objectives are the same when not augmented by increasing supposed need to combine knowledge from many disciplines, multidisciplinary, transdisciplinary. What is particularly difficult when the new students have, every year, more difficulties to develop the specific content, the more their involvement multi/transdisciplinary. Anyway, this challenge is in the hands of teachers.

Education can be evaluated as a process in which knowledge "produces, reproduces, is preserved, is systematized, organizes, transmitted and becomes universal," spreading their results in society [14].

In this scenario, there is a general concern about the quality of education in Brazil. There is universal agreement that the human learning process is itself extremely complex and surrounded by a very wide range of variables. A challenge discussed and conducted at the University Positive is the organization and planning of institutional classes [1].

To help teachers in this challenge, the Bloom's Taxonomy of Learning Levels [4] may be a valid reference in the structuring of teaching, because brings us a sketch of what should be learned before or after, or how high (or not) is learning.
So the next section presents the structure of knowledge established by Bloom. In the subsequent section, it discusses how this structure was used for content organization in a specific course. Subsequently, discussions are drawn on this approach.

\section{Learning Levels in Bloom's Taxonomy}

The Taxonomy of Educational Objectives of Bloom [4], revised by Anderson [2], defines a six-level hierarchy for the cognitive process. Each level of this structure is a cognitive ability. Classification, starting from the lowest level to the highest of cognitive process, according to Ref. [6], is:

(1) Remember: this level is defined by the ability to recover, recognize, recall relevant knowledge through long-term memory;

(2) Understand: the construction of meaning through speaking, writing or graphics for interpreting, exemplifying, classifying, summarizing, inferring, comparison and explanation;

(3) Apply: the ability to make or use a procedure running it, or implementing it;

(4) Analyze: separate a matter in its constituent parts, determining how the parts relate to each other and to the structure as a whole or its purpose through differentiation, organization and allocation;

(5) Evaluate: make judgments based on criteria and standards through checking and criticism;

(6) Create: add elements to form a coherent or functional whole; reorganize elements into a new pattern or structure through the generation, production, or planning.

The last three skills (analyze, evaluate and create) belong to the highest level of classification, the metacognitive level.

The level of learning in higher education should reach the highest levels in this classification, assuming that a higher level of learning may mean a greater probability, at least from a technical point of view, that the graduate can assume its proper role in the midst of a society that demands your participation. 


\section{The Course and Bloom's Taxonomy}

Initially, we present the discipline and its context in Computer Engineering Program. Then, we present a sample of their structuring according to Bloom's Taxonomy of Educational Objectives.

\subsection{The Course}

The Computer Engineering Program at the University Positive [10] occurs in two shifts, morning and night, both lasting five years. Your organization is annual serial. Each series is fractionated into four evaluation times.

The digital systems discipline occurs in the third year and has total workload of 160 classroom hours (1 classroom hour $=50 \mathrm{~min}$ ), also divided into theoretical and practical activities. Thus, each quarter of the course has duration of 40 classroom hours. At least twenty percent of their workload is intended for supervised practical activities that occur outside the classroom, completing a full course load of $160 \mathrm{~h}$.

This course is preceded by the discipline of mathematical logic, of the first series, which develops related content such as Boolean algebra and its relationship with logic circuits. In the second series, we have the electronics course, which provides the basis of electricity and electronics. In third series, so concomitant to digital systems, there is the architecture and computer organization course, which develops review of the logical area of content and apply concepts developed in digital systems, as the structure of registers, data flow structure controlled by multiplexers, the operation of logic and arithmetic units, among other topics.

From this rationale and electronics, digital systems in its first quarter does the transposition from analog electronics, which was studied in the previous series, to electronic of digital devices, culminating in the study of digital integrated circuit technologies, its parameters and characteristics. The second quarter has its focus shifted from the electronic world to the formation of logical structures as the memory elements (latches and flip-flops) and elementary sequential machines (such as counter circuits and basic controllers, for example), multiplexers and demultiplexers, encoders and decoders, transcoders, and their applications.

The third quarter is centered in programmable logic devices and in digital systems design using hardware description language. The fourth quarter addresses the design of synchronous sequential machines and an integrated project, for example, a processor architecture CISC (complex instruction set computer).

After this brief description, the next section shows an example of structure for content development in this course.

\subsection{Applying the Bloom's Taxonomy}

Pilla and Ferlin [8] present a summary of how the Taxonomy of Educational Objectives Bloom influenced the structure of the evaluation system of this discipline. In this work, the central focus is on the description of the development of the activities of a quarter.

As already explained above in Section 2, the objective to be achieved is to lead the student learning to the metacognitive stage in the context of discipline. Let us take as an example an isolated content of the second quarter of discipline, storage elements and applications (asynchronous sequential machines). The development of this content suggests the use of some classes, both theoretical and practical.

The topic begins with the presentation of the most basic memory element, the so-called "basic latch", as shown in Fig. 1, which is useful for demonstrating the "memory effect" and attracts an initial focus of the student addressing the possible uses of it. The students easily "understand" (second level of Taxonomy) its operating principle, and is able to reproduce it.

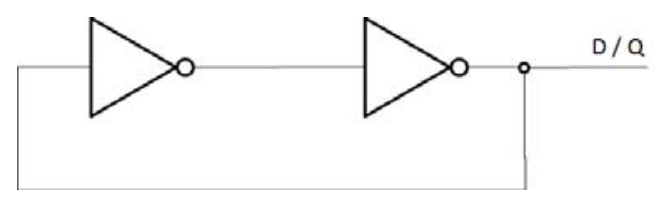

Fig. 1 The basic "Latch". 
After this initial step, almost purely motivational, we can discuss the architecture and the operating principle of the RS latch (Fig. 2), through the representation of a logical sequence (series of steps by which a specific logical combination is applied to inputs $\mathrm{R}$ and $\mathrm{S}$ to assess the results on the outputs $\mathrm{Q}$ and/Q) that highlights the main device operating capabilities. Following this order, it is still not possible to assess whether the student will be able to "remember" (long-term effect), but it is possible to assess whether "understood" by proposing to exercise a new and particular circuit evaluation sequence to be developed right away.

It is clear that the verification of "understand" of this specific mechanism requires the ability to "analyze" due to content considered prerequisites (in this case the very Boolean algebra). When requesting the student's participation in an exercise at least the memorization process ("remember") is reinforced.

Still regarding the RS latch of Fig. 2, we need to reach higher levels. We can test the "apply", suggesting as exercise the classic example of the anti-bouncing circuit having a possible response in Fig. 3. You can ask the student to "create" a circuit that, from the functional characteristics of the RS latch, is able to eliminate the undesirable effect of "bouncing" of the mechanical switches, a common problem in interfacing with digital systems. If used at another time, the same problem proposed simply as "design a circuit based on digital devices to eliminate electrical noise produced by mechanical switches" would be an attempt to reach the level "create". Already the "to analyze" could be achieved presenting the student with a solution and wondering "how" works. The "evaluate" could be applied by requesting a comparison of approaches used in two or more
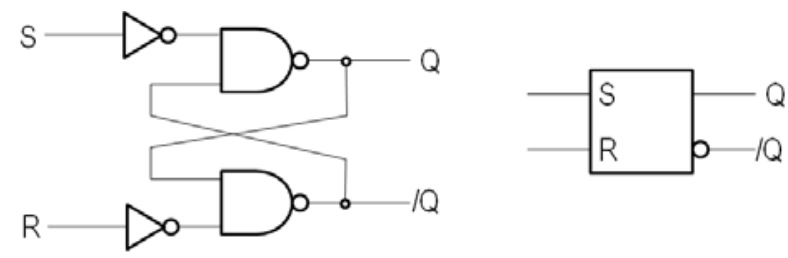

Fig. 2 The RS “latch" (left) and its logical symbol (right).

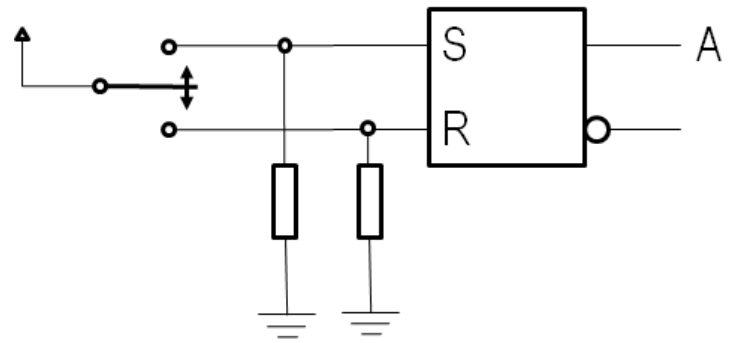

Fig. 3 Anti-boucing circuit.

different solutions. What is the "best", in which "case", under which "criteria”?

\section{Discussion}

Section 3 presented in detail the application of Bloom's Taxonomy of Educational Objectives through a punctual example. It is possible to see that the attempt to reach all levels in each content element can be an exhaustive process, and it will be up to the teacher to establish what content, in what order and at what time this should really be applied.

This process will be completed in the stage of the evaluation, which should also be sliced to check the levels of learning. The teacher has to determine whether the of training objectives of the course if only metacognitive levels (the last three) are acceptable, or if occasionally the lower levels should also (or not) are subject to evaluation.

\section{Conclusions}

The question should then be drawn up is: If the end of the course, applied all evaluation procedures of verification of learning, this reached the expected result? First it is important to bear in mind that the expected ideal is the ability to create. In this sense, a qualitative assessment the answer is sometimes "yes", and in most cases, the answer is "no". This is because many students have not acquired the maturity to independent thinking that these levels require.

However, the levels of analysis, and the previous hierarchy, are common to students who passed the course. One issue that still remains to be answered is: What factors are the main impediments for the vast majority of students reach both higher cognitive levels? 
An external qualitative analysis to discipline (for example, the experience in orientation in TCC (completion of course work)) a response may be the time needed for maturation.

Although the discipline has an annual basis, some students probably would have to have spent more time on their studies and activities of discipline. For others, the lack of greater exposure to lab activities and project, to be developed as a team could help explain this lack of maturity. Note also that sometime after performed discipline, and processed through other more or even less related disciplines, understanding expands because concepts are matured.

This is due to the relationship with new knowledge and the expansion of circulation and, therefore, the overview that the student himself begins to establish its own course, which is still heavily influenced by practical needs as internships and jobs, as well as interests personal. Thus, we can conclude that the ultimate goal of discipline, which is to take the learning level to the cognitive level of creation, is not fully achieved for all students during the course. However, a minimum level corresponding to the analysis is usually achieved and those by special interest wishing to reach the highest levels supported for both. So that the maximum level was reached you can see that a clear path is the expansion time devoted to activities and content by the students.

The teaching interference in the process are possible, particularly in the search for an expansion of interest by the student, but the ultimate success to be achieved still depends directly on the expansion of the dedication of it. Pilla and Ferlin [8] have made a brief discussion of the evaluation process of this same discipline also from the perspective Bloom's Taxonomy.

\section{References}

[1] Aguiar, G. F. 2010. "How to Conquer Undergraduate
Students? Successful Approaches in Universidade Positivo." Presented at the XXXVIII-Brazilian Engineering Education Congress, Fortaleza.

[2] Anderson, L. W., and Krathwohl, D. A. 2001. Taxonomy for Learning, Teaching, and Assessing. New York: Longman, 2001.

[3] ANDIFES. Seminar Andifes Quality High School Debate. Accessed May 24, 2013. http://www.andifes. org.br/?p=17471.

[4] Bloom, B. S. 1956. Taxonomy of Educational Objectives: The Classification of Educational Goals: Handbook I, Cognitive Domain. New York: Longman.

[5] Filho, A. B. C., Ferreira, L. F., Bercht, M., Tarouco, L. M. R., and Lima, J. V. 2012. "Learning Objects in supporting Engineering Learning: Exploring the extrinsic motivation.” Magazine New Technologies in Education 10 (3). Accessed January 20, 2015. http://seer.ufrgs.br/index.php/renote/article/view/3690.

[6] Forehand, M. 2010. "Bloom's Taxonomy-Emerging Perspectives on Learning, Teaching and Technology.” The University of Georgia.

[7] GERAES. Promedio-Improving the Quality and Efficiency of High School. Accessed May 24, 2013. http://www.geraes.mg.gov.br/projetos-estruturadores/prot agonismo-juvenil/promedio.

[8] Pilla, Jr, V., and Ferlin, E. P. 2011. “The Bloom's Taxonomy of Learning Levels Applied on a Discipline of Computer Engineering Course.” Presented at the XXXIX Brazilian Congress on Engineering Education, Blumenau.

[9] Portilho, E. 2009. How to Learn? Strategies, Style and Metacognition. Rio de Janeiro: WAK Ed.

[10] Positivo University. Political and Educational Project of Computer Engineering Course. Positivo University, Computer Engineering Course 2011.

[11] Severino, A. J. 2008. Methodology of Scientific Work. 23. rev. Ed. is updated. São Paulo: Editora Cortez.

[12] Silveira, G. T. 2013. "Universal and Quality in High School.” Journal UNESP 22, June. Accessed on: May 24, 2013. http://www.unesp.br/aci/jornal/212/supleb.php.

[13] UFSC. Increases the Demand of Students for Engineering Courses. Accessed May 24, 2013. http://ctc.paginas.ufsc.br/2013/04/16/aumenta-a-procurade-estudantes-pelos-cursos-de-engenharia/.

[14] Vasconcellos, C. S. 1995. Planning: Teaching and Learning Plan and Educational Project-Methodological Elements for Design and Realization. Vol. 1. São Paulo: Pedagogical Notebooks of Libertad. 